\title{
Antidepressant-Like Effects of Psoralen Isolated from the Seeds of Psoralea corylifolia in the Mouse Forced Swimming Test
}

\author{
Qun Xu, ${ }^{a}$ Ying Pan, ${ }^{a}$ Li-Tao YI, ${ }^{a}$ Yu-Cheng LI, ${ }^{a}$ Shi-Fu Mo, ${ }^{a, c}$ Fu-Xin Jiang, ${ }^{a}$ Chun-Feng QiaO, ${ }^{c}$ \\ Hong-Xi Xu, ${ }^{c}$ Xiao-Bo Lu, ${ }^{b}$ Ling-Dong Kong, ${ }^{*, a, b}$ and Hsiang-Fu KunG ${ }^{*, b}$ \\ ${ }^{a}$ State Key Laboratory of Pharmaceutical Biotechnology, School of Life Sciences, Nanjing University; Nanjing 210093, \\ P. R. China: ${ }^{b}$ Center for Emerging Infectious Diseases, Faculty of Medicine, The Chinese University of Hong Kong; \\ Shatin, N. T. Hong Kong, P. R. China: and ${ }^{c}$ Chinese Medicine Laboratory, Hong Kong Jockey Club Institute of Chinese \\ Medicine; No. 2 Biotechnology Avenue, 12 Miles, Tai Po Road, Shatin, Hong Kong, P. R. China.
}

Received September 27, 2007; accepted March 12, 2008; published online March 21, 2008

\begin{abstract}
The forced swimming test (FST) is suggested to produce abnormalities in the serotonergic and hypothalamic-pituitary-adrenal (HPA) axis systems. Therefore, compounds that attenuate these neurobiological alterations may have potential as antidepressants. The behavioral and biochemical effects of psoralen, a major furocoumarin isolated from Psoralea corylifolia, were investigated in the FST model of depression in male mice. Psoralen significantly reduced immobility and increased swimming without altering climbing in the mouse FST. Psoralen remarkably reversed FST-induced alterations in serotonin (5-HT) and 5-hydroxyindoleacetic acid (5-HIAA) levels in frontal cortex and hippocampus in mice. Furthermore, psoralen attenuated FST-induced elevations in serum corticotropin-releasing factor (CRF) and corticosterone concentrations to normalize the HPA axis activity. These results suggested that psoralen possessed potent antidepressant-like properties which were at least in part mediated by improving the abnormalities in the serotonergic and the HPA axis systems.
\end{abstract}

Key words psoralen; forced swimming test; serotonin; hypothalamic-pituitary-adrenal axis

Depression is associated with behavioral disturbances and serotonergic and neuroendocrinological disfunctions. ${ }^{1,2)}$ The brain serotonergic system is a very complicated control system playing an important role in the response to depression. ${ }^{3)}$ A number of factors have been proposed to account for a reduced functionality of serotonergic system in depression. Investigations based on this system have formed into currently available antidepressants. ${ }^{2}$ On the other hand, neuroendocrinological abnormality in depressed patients is hyperactivity of the hypothalamic-pituitary-adrenal (HPA) axis characterized by hypersecretion of corticotropin-releasing factor (CRF), which stimulates corticosterone release. ${ }^{4,5)}$ Successful antidepressant treatment could attenuate these alterations in clinical trials and animal experiments. ${ }^{6-9)}$ In addition, there is a close relationship between the serotonergic and HPA axis systems in major depression. ${ }^{10-13)}$ The impact of stress on the HPA axis is reviewed and evidence present that CRF is the stress neurotransmitter which plays an important role in the activation of serotonergic systems..$^{11,14)}$

Psoralen (Fig. 1) is a main furocoumarin isolated from the seeds of Psoralea corylifolia, ${ }^{15)}$ which is a traditional Chinese medicine used to treat a wide range of diseases and conditions. Our previous studies demonstrated that the total furocoumarins extracts of $P$. corylifolia possessed the potent antidepressant properties by employing the forced swimming test (FST), a well-established animal model of depression. ${ }^{7}$ These furocoumarins extracts depressed the hyperactive HPA axis induced by swim stress in mice. ${ }^{7)}$ Furthermore, the total furocoumarins extracts and psoralen exhibited inhibitory actions on monoamine oxidase (MAO) A and B activities. ${ }^{16,17)}$ Per-orally administered psoralen increased the daytime levels

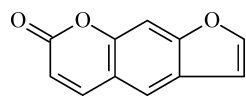

Fig. 1. Structure of Psoralen of melatonin via the competitive inhibition of hepatic melatonin metabolism, indicating that psoralen might affect seasonal affective disorder patients under a low level of illumination. ${ }^{18)}$ However, there is no study on antidepressant-like effects and related possible mechanisms of actions by psoralen. The aim of the current study was to investigate the effects of psoralen on the durations of immobility, climbing and swimming in the mouse FST after administrations for 1, 3, 7 and $14 \mathrm{~d}$, respectively. We also examined the effects of 14-d psoralen treatment on serotonergic neurotransmitters serotonin (5-HT) and its metabolite 5-hydroxyindoleacetic acid (5-HIAA) levels in frontal cortex and hippocampus of the mouse brain regions. The regulation of psoralen on the HPA axis including CRF and corticosterone concentrations was simultaneously studied in the mouse FST.

\section{MATERIALS AND METHODS}

Materials Psoralen was isolated and purified from the seeds of $P$. corylifolia as described in our previous reports. ${ }^{19)}$ The purity of the chemical was determined to beyond $98 \%$ by HPLC analysis. Amitriptyline was obtained from Changzhou Siyao Pharmaceuticals Co., Ltd. (P. R. China). All other chemicals were of high-purity analytical grade obtained from commercial sources (P. R. China).

Animals Male ICR strain of mice (Laboratory Animal Centre, Nanjing University of Traditional Chinese Medicine, Jiangsu Province, P. R. China), weighing 23-25 g, was used. Animals were housed 5 per cage $(320 \times 180 \times 160 \mathrm{~cm})$ under a normal $12 \mathrm{~h}$ light/dark schedule with the lights on at 07:00 a. m. and had free access to tap water and food pellets. Ambient temperature and relative humidity were maintained at $22 \pm 2{ }^{\circ} \mathrm{C}$ and at $55 \pm 5 \%$, respectively. They were allowed at least one week to adapt to the laboratory environments before experiments. Experiments, performed by an observer who was unaware of the treatment each mouse had received, 
were carried out between 13:00 p.m. and 15:00 p.m.

All studies were conducted in accordance with the Institutional Animal Care Committee at the Nanjing University and the China Council on Animal Care at Nanjing University.

Drug Administration in Mice Drugs were freshly dispersed in water. All doses were expressed as milligrams per kilogram body weight of the respective drugs. Food, but not water, was withdrawn from the animals $1.5 \mathrm{~h}$ prior to drug administration. For the behavioral tests, four groups (vehicle control) were administered with water for $1,3,7$ and $14 \mathrm{~d}$, respectively. Another sixteen groups receiving psoralen (10, $20,40 \mathrm{mg} / \mathrm{kg})$ and amitriptyline $(10 \mathrm{mg} / \mathrm{kg})$ were administered in a volume of $10 \mathrm{ml} / \mathrm{kg}$ for $1,3,7$ and $14 \mathrm{~d}$, respectively. For the biochemical experiments, five groups exposed to FST and other five groups not exposed to FST were administered with water (vehicle), psoralen $(10,20,40 \mathrm{mg} /$ $\mathrm{kg}$ ) and amitriptyline $(10 \mathrm{mg} / \mathrm{kg})$ for $14 \mathrm{~d}$, respectively. All drugs were given by gastric gavages once daily at 11:00 a.m.-12:00 p.m., and the behavioral tests were carried out $1 \mathrm{~h}$ after the last treatment.

FST in Mice The procedure developed originally by Porsolt et al., ${ }^{20)}$ and modified by Lucki and co-workers ${ }^{21-23}$ ) was employed. Briefly, mice were individually placed in a glass cylinder ( $20 \mathrm{~cm}$ in height, $14 \mathrm{~cm}$ in diameter) filled 10 $\mathrm{cm}$ high with water $\left(25 \pm 2{ }^{\circ} \mathrm{C}\right)$. All animals were forced to swim for $6 \mathrm{~min}$, and the duration of immobility, swimming and climbing was observed and measured during the final 4 min interval of the test, respectively. All test swim sessions were recorded by a video camera positioned directly above the cylinder. Two competent observers, who were unaware of the treatment each mouse had received, scored the videotapes. Immobility period was regarded as the time spent by the mouse floating in the water without struggling and making only those movements necessary to keep its head above the water. The predominant behavior was assigned to one of three categories: immobility, swimming and climbing. At the end of each swimming test, the mice were dried with paper towels, placed in heated cages for $15 \mathrm{~min}$, and then returned to their housing condition. The animals were used only once in each swimming test.

Blood and Tissue Sample Collection The FST-treated and the control mice receiving drugs for $14 \mathrm{~d}$ were used for the determinations of 5-HT, 5-HIAA, CRF and corticosterone, levels. To avoid fluctuations on hormone levels due to circadian rhythms, animals were bled between 13:00 p.m. and 15:00 p.m. on the day of sacrifice. Blood was collected on ice and separated in a refrigerated centrifuge at $4{ }^{\circ} \mathrm{C}$. Serum was stored at $-80^{\circ} \mathrm{C}$ until CRF and corticosterone assays were performed. The brain regions frontal cortex and hippocampus were carefully dissected and stored at $-80^{\circ} \mathrm{C}$ for determinations of 5-HT and 5-HIAA levels.

Determination of 5-HT and 5-HIAA Levels 5-HT and 5-HIAA levels in frontal cortex and hippocampus were determined by modification of method. ${ }^{24,25)}$ Briefly, the each brain region was homogenized in acidified $n$-butanol and shaken for $5 \mathrm{~s}$, then centrifuged at $3000 \times \boldsymbol{g}$ for $5 \mathrm{~min}$ at $4{ }^{\circ} \mathrm{C}$. The supernatant was mixed with $n$-heptanes and $0.1 \mathrm{M} \mathrm{HCl}$, shaken for $30 \mathrm{~s}$ and centrifuged at $3000 \times \boldsymbol{g}$ for $5 \mathrm{~min}$ at $4{ }^{\circ} \mathrm{C}$. The aqueous phase for determination of 5-HT, and the organic phase for determination of 5-HIAA were retained, respectively. 5-HT and 5-HIAA concentrations were calculated by interpolation of its respective standard curves. Obtained values were reported in $\mathrm{ng} / \mathrm{g}$ of wet tissue. The ratio of 5-HIAA/5-HT was used as an index of the 5-HT turnover. ${ }^{26)}$

Determination of Serum CRF Levels Serum CRF levels were measured using the commercially available radioimmunoassay kits of Navy Radioimmunoassay Technique Center in Beijing, P. R. China. The sensitivity of the assay was $0.2 \mathrm{ng} / \mathrm{ml}$. Intra- and inter-assay coefficients of variation for this assay was less than $8 \%$.

Determination of Serum Corticosterone Levels Serum corticosterone levels were measured using an enzyme immunoassay kit (Adlitteram Diagnostic Laboratories Inc.). The minimum detectable concentrations of corticosterone in this assay were estimated to be $0.1 \mathrm{nmol} / 1$.

Statistical Analyses Data were expressed as the mean \pm S.E.M. Statistical differences were evaluated using Student's $t$-test and One-way ANOVA following by Dunnett test via the Statistical Analysis System (GraphPad Prism 4, GraphPad Software, Inc., San Diego, CA, U.S.A.). For all the analyses, a value of $p<0.05$ was considered statistically significant.

\section{RESULTS}

Effects of Psoralen on Immobility, Climbing and Swimming Behaviors in the Mouse FST The effects of psoralen and amitriptylin on immobility, climbing and swimming behaviors in the mouse FST were shown in Fig. 2. As shown in Fig. 2A, after 1-d treatment, psoralen at 10 and $20 \mathrm{mg} / \mathrm{kg}$ only showed a slight reduction in immobility, but $40 \mathrm{mg} / \mathrm{kg}$ psoralen significantly decreased immobility $(p<0.01)$. Psoralen exhibited a slight but insignificant dosedependent increase in swimming. Psoralen treatment at the three doses failed to alter climbing. Amitriptyline at $10 \mathrm{mg} / \mathrm{kg}$ significantly reduced immobility $(p<0.01)$ without change in swimming and climbing.

As shown in Fig. 2B, after 3-d treatment, psoralen at $10 \mathrm{mg} / \mathrm{kg}$ had no effect on immobility in the mouse FST. As the doses of psoralen increased from 20 to $40 \mathrm{mg} / \mathrm{kg}$, immobility was significantly decreased $(p<0.05, p<0.05$, respectively), with a slight inverted U-shaped dose-dependent relationship. Psoralen at $10 \mathrm{mg} / \mathrm{kg}$ showed a slight increase in swimming, but 20 and $40 \mathrm{mg} / \mathrm{kg}$ psoralen remarkably increased swimming ( $p<0.01, p<0.01$, respectively), resulting in an inverted U-shaped dose-response tendency. However, psoralen at the three doses did not change climbing. Amitriptyline at $10 \mathrm{mg} / \mathrm{kg}$ significantly decreased immobility $(p<0.001)$ and increased swimming $(p<0.001)$ without affecting climbing.

As shown in Fig. 2C, after 7-d treatment, psoralen at $10 \mathrm{mg} / \mathrm{kg}$ significantly decreased immobility $(p<0.05)$, however, the effects of 20 and $40 \mathrm{mg} / \mathrm{kg}$ psoralen did not reach statistical significance. Psoralen at $10 \mathrm{mg} / \mathrm{kg}$ produced a slight but insiginificant increase in swimming, but 20 and $40 \mathrm{mg} / \mathrm{kg}$ psoralen significantly increased swimming $(p<$ $0.01 ; p<0.05$ respectively), exhibiting an inverted U-shaped dose-response relationship. Psoralen did not influence climbing. Amitriptyline at $10 \mathrm{mg} / \mathrm{kg}$ failed to affect animal behaviors in this study.

As shown in Fig. 2D, after 14-d treatment, psoralen had effects on immobility at 10, 20 and $40 \mathrm{mg} / \mathrm{kg}(p<0.05 ; p<$ 
(A)

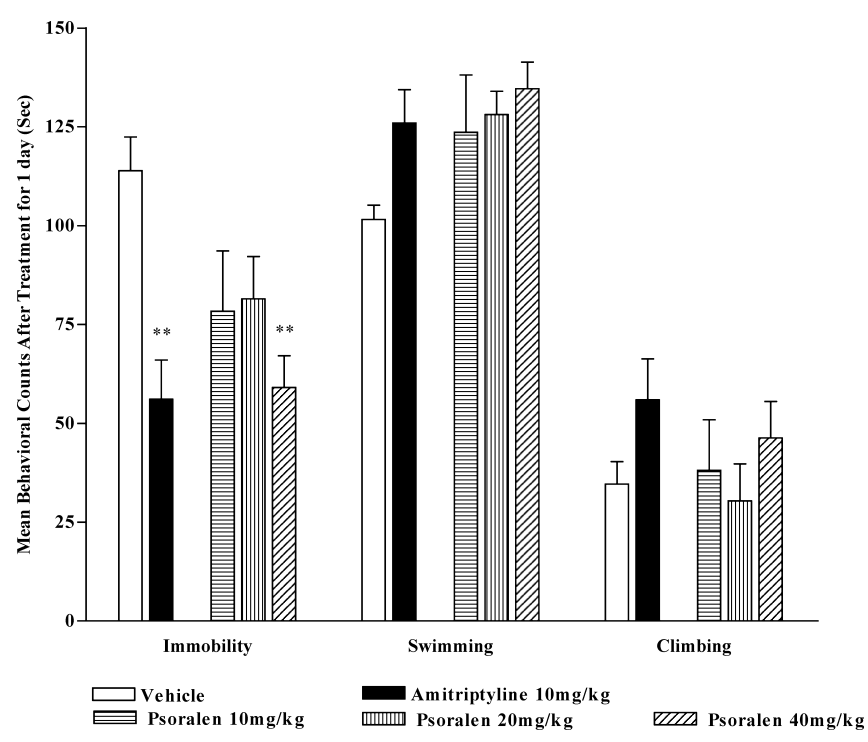

(C)

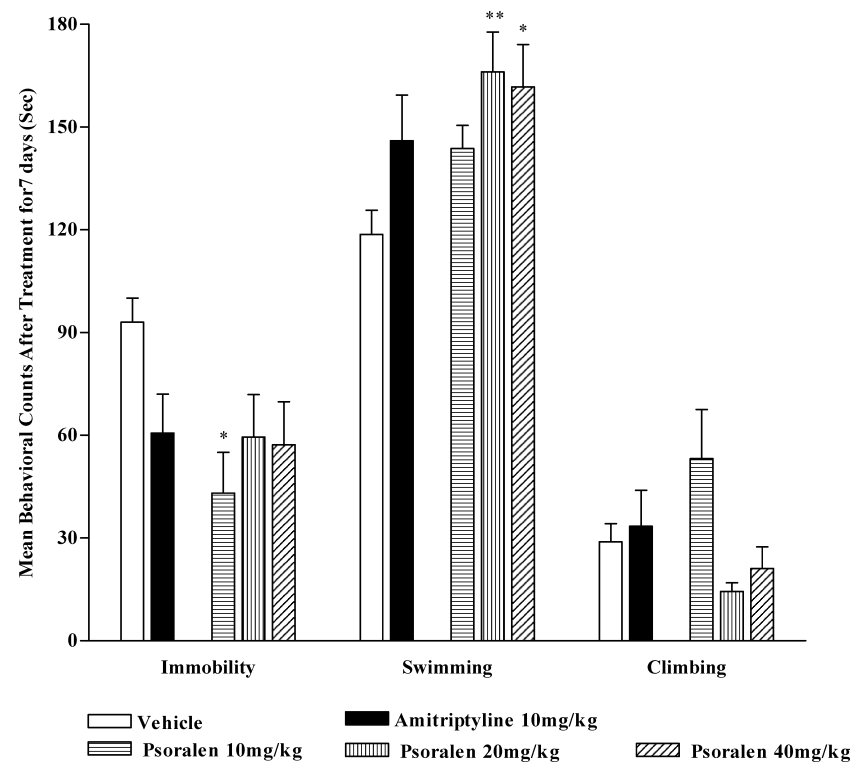

(B)

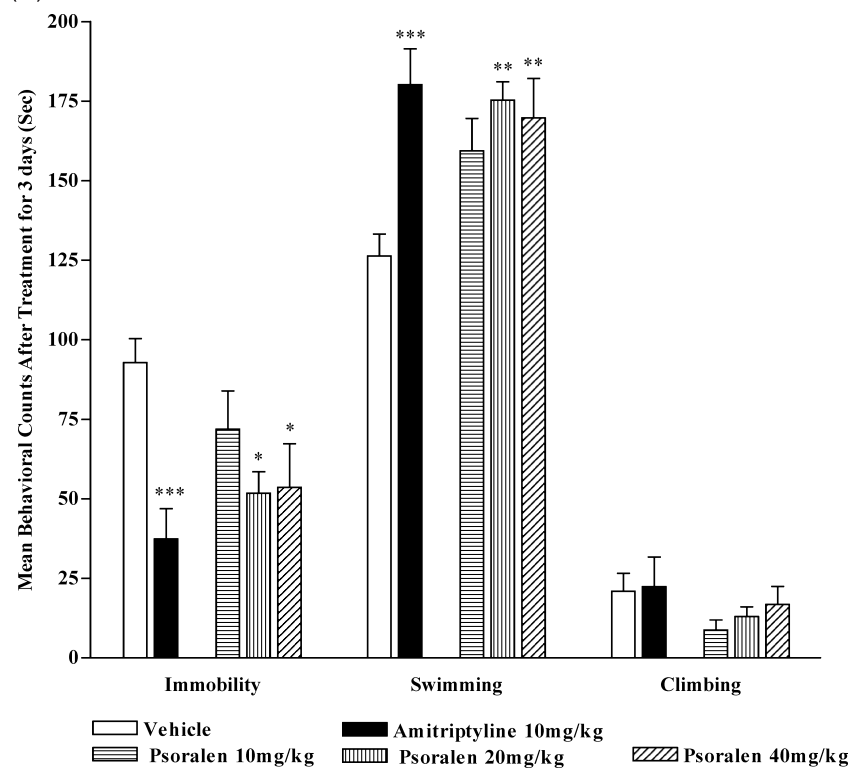

(D)

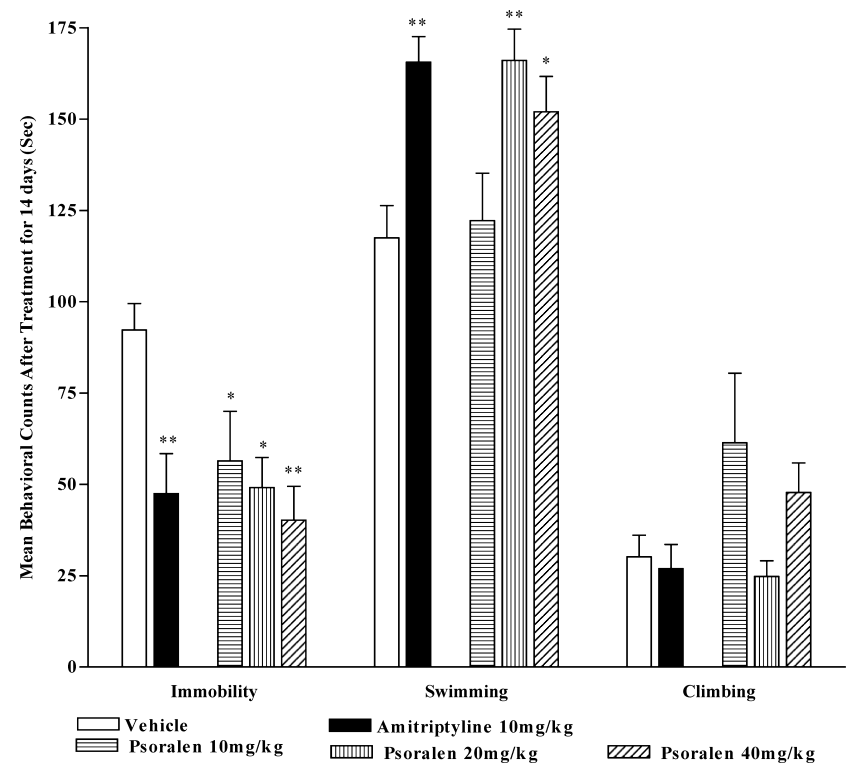

Fig. 2. Effects of Psoralen on Immobility, Climbing and Swimming Behaviors in the Mouse FST

Psoralen (10, 20, $40 \mathrm{mg} / \mathrm{kg}$ ), amitriptyline (10 mg/kg) and water (vehicle) were orally administered for 1 (Fig. 2A), 3 (Fig. 2B), 7 (Fig. 2C) and 14 (Fig. 2D) consecutive days, respectively. The data were given as the mean \pm S.E.M. $* p<0.05 ; * * p<0.01$ and $* * * p<0.001$ when compared to the control animals (vehicle). The number of animals in each group was 10 .

$0.05 ; p<0.01$, respectively), producing a linear dose-response tendency on immobility reduction in the mouse FST. Psoralen at $10 \mathrm{mg} / \mathrm{kg}$ only showed a slight increase in swimming, but 20 and $40 \mathrm{mg} / \mathrm{kg}$ psoralen significantly increased swimming ( $p<0.01, p<0.05$, respectively), exhibiting an inverted U-shaped dose-response relationship. Psoralen treatment also did not influence climbing. Amitriptyline at $10 \mathrm{mg} / \mathrm{kg}$ significantly decreased immobility $(p<0.01)$ and increased swimming $(p<0.01)$, without changing climbing.

Effects of Psoralen on 5-HT, 5-HIAA Levels and 5HIAA/5-HT Ratio in Different Brain Regions in the Mouse FST Figure 3 showed the effects of psoralen and amitriptyline after 14-d treatment on 5-HT, 5-HIAA levels and 5-HIAA/5-HT ratio in frontal cortex and hippocampus of the mouse brain in the FST.
In frontal cortex, a one-way ANOVA revealed that FST caused a significant decrease in 5-HT levels $(p<0.01)$ with a slight change in 5-HIAA levels, resulting in an elevation in 5-HIAA/5-HT ratio $(p<0.01)$. When compared to the FSTtreated vehicle, psoralen at $20 \mathrm{mg} / \mathrm{kg}$ significantly increased 5 -HT levels $(p<0.05)$, but 10 and $40 \mathrm{mg} / \mathrm{kg}$ psoralen treatment only slightly elevated 5-HT levels. An inverted Ushaped dose-response relationship on 5-HT levels was observed in this study. Psoralen decreased 5-HIAA levels, only the dose of $40 \mathrm{mg} / \mathrm{kg}$ produced a significant decrease $(p<$ 0.01), showing a slight dose-response relationship. Furthermore, a one-way ANOVA yielded that $10 \mathrm{mg} / \mathrm{kg}$ psoralen exhibited a slight decrease in 5-HIAA/5-HT ratio, and 20 and $40 \mathrm{mg} / \mathrm{kg}$ psoralen decreased the ratio in the mouse FST $(p<$ $0.01, p<0.001$, respectively), exhibiting a linear dose-re- 

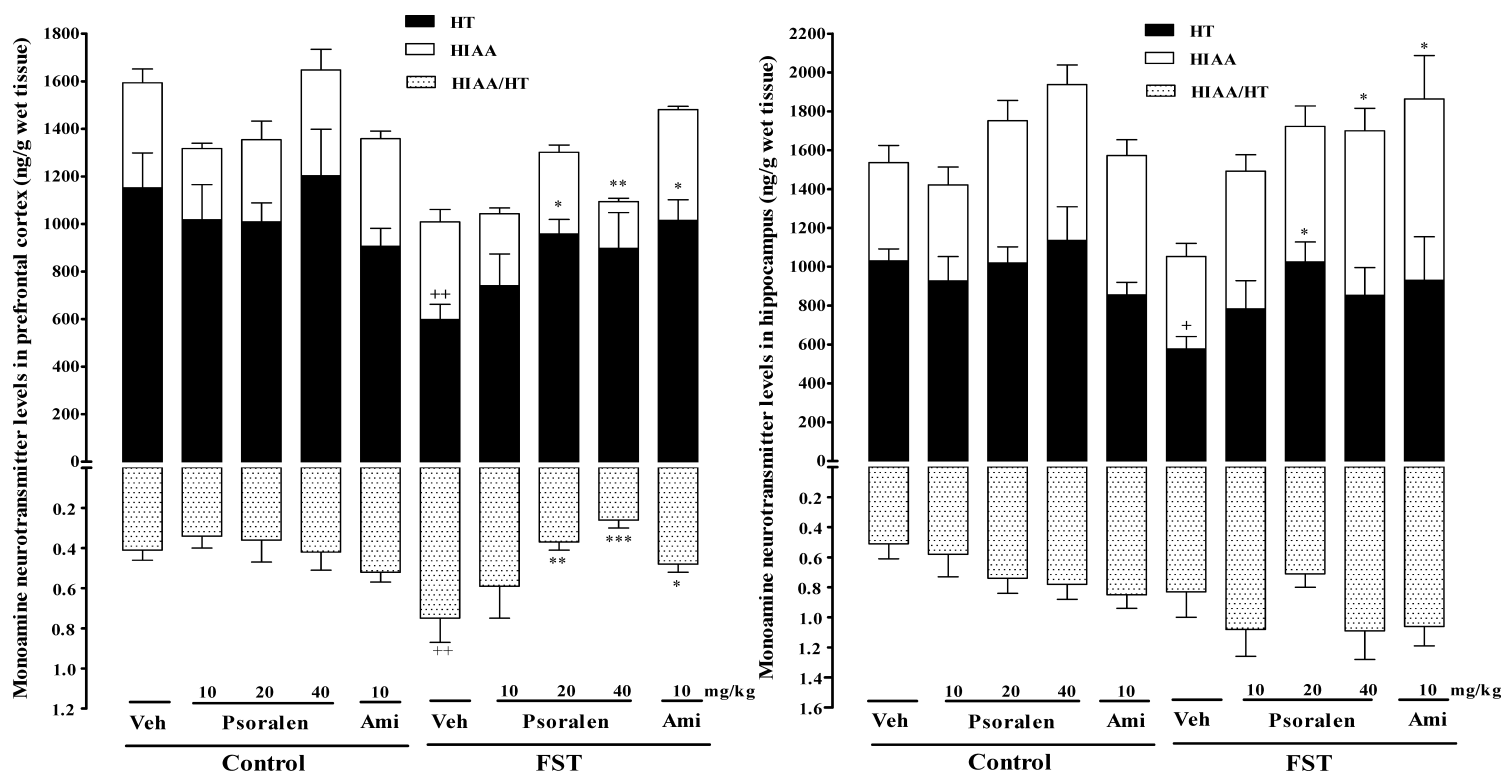

Fig. 3. Effect of Psoralen on 5-HT, 5-HIAA Levels and 5-HIAA/5-HT Ratio in the Different Brain Regions in the Mouse FST

Psoralen $(10,20,40 \mathrm{mg} / \mathrm{kg}$ ), amitriptyline $(\mathrm{Ami}, 10 \mathrm{mg} / \mathrm{kg}$ ) and water (vehicle) were orally administered for 14 consecutive days, respectively. The data were given as the mean \pm S.E.M. For statistical significance, $* p<0.05$, $* * p<0.01$ and $* * * p<0.001$ when the drug treated groups were compared with the FST-treated mice (FST vehicle). $+p<0.05$ and $++p<0.01$ when the drug treated groups were compared with the non-stressed mice (Control vehicle). The number of animals in each group was 8.

sponse tendency. Amitriptyline at $10 \mathrm{mg} / \mathrm{kg}$ increased $5-\mathrm{HT}$ levels $(p<0.05)$ but failed to alter 5-HIAA levels, resulting in a reduction of 5-HIAA/5-HT ratio $(p<0.05)$ in this study.

In hippocampus, a one-way ANOVA revealed that FST caused a significant reduction in 5-HT levels $(p<0.05)$ without change in 5-HIAA levels, producing a slight but insignificant increase of 5-HIAA/5-HT ratio. When compared to the FST-treated vehicle, psoralen at $20 \mathrm{mg} / \mathrm{kg}$ significantly increased 5-HT levels $(p<0.05) .10$ and $40 \mathrm{mg} / \mathrm{kg}$ psoralen treatment only slightly increased 5-HT levels. A slightly inverted U-shaped dose-response tendency on 5-HT levels was observed. Psoralen at 10 and $20 \mathrm{mg} / \mathrm{kg}$ did not affect 5-HIAA levels, but $40 \mathrm{mg} / \mathrm{kg}$ psoralen significantly increased 5 -HIAA levels $(p<0.05)$. Psoralen treatment failed to alter 5-HIAA/5HT ratio. Amitriptyline only increase 5-HIAA levels $(p<$ 0.05 ) in this study.

There was no significant alteration of 5-HT, 5-HIAA levels and 5-HIAA/5-HT ratio in frontal cortex and hippocampus of the control animals not exposed to FST after psoralen and amitriptyline treatments.

Effects of Psoralen on Serum CRF Levels in the Mouse FST The effects of psoralen and amitriptyline after 14-d treatments on serum CRF concentrations in the mouse FST were showed in Fig. 4. A one-way ANOVA revealed that FST produced a significant elevation in serum CRF levels in mice $(p<0.001) .10 \mathrm{mg} / \mathrm{kg}$ psoralen slightly reduced serum CRF concentrations in the FST-treated animals. Psoralen at 20 and $40 \mathrm{mg} / \mathrm{kg}$ remarkably reversed the elevated CRF concentrations caused by FST when compared to the FST-treated vehicle ( $p<0.05, p<0.05$, respectively), exhibiting a slight inverted U-shaped dose-response relationship. Amitriptyline at $10 \mathrm{mg} / \mathrm{kg}$ had no effect on CRF concentrations in the mouse FST in this study. In addition, psoralen and amitriptyline did not yield any significant effect on serum CRF levels in the control animals not exposed to FST.

Effects of Psoralen on Serum Corticosterone Levels in

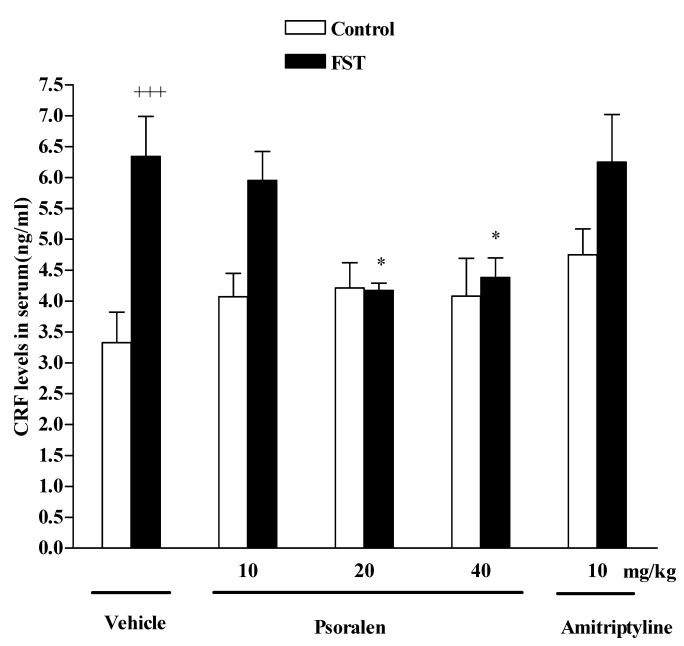

Fig. 4. Effects of Psoralen on Serum CRF Levels in the Mouse FST

Psoralen $(10,20,40 \mathrm{mg} / \mathrm{kg})$, amitriptyline $(10 \mathrm{mg} / \mathrm{kg})$ and water (vehicle) were orally administered for 14 consecutive days, respectively. The data were given as the mean \pm S.E.M. For statistical significance, $* p<0.05$ when the drug treated groups were compared with the FST-treated mice (FST vehicle). $+++p<0.001$ when the drug treated groups were compared with the non-stressed mice (Control vehicle). The number of animals in each group was 8 .

the Mouse FST The effects of psoralen and amitriptyline after 14-d treatments on serum corticosterone levels in the FST in mice were showed in Fig. 5. A one-way ANOVA revealed that serum corticosterone concentrations in the FSTtreated vehicle was significantly higher than that in the control vehicle $(p<0.01)$. Psoralen at 10 and $40 \mathrm{mg} / \mathrm{kg}$ significantly reduced FST-induced increase in serum corticosterone levels ( $p<0.05, p<0.05$, respectively), however, the effect of $20 \mathrm{mg} / \mathrm{kg}$ psoralen did not reach statistical significance. And there was no clear dose-response tendency. Treatment with amitriptyline significantly prevented swim stress-induced elevation in serum corticosterone concentrations $(p<0.01)$. Psoralen and amitriptyline showed no significant change in 


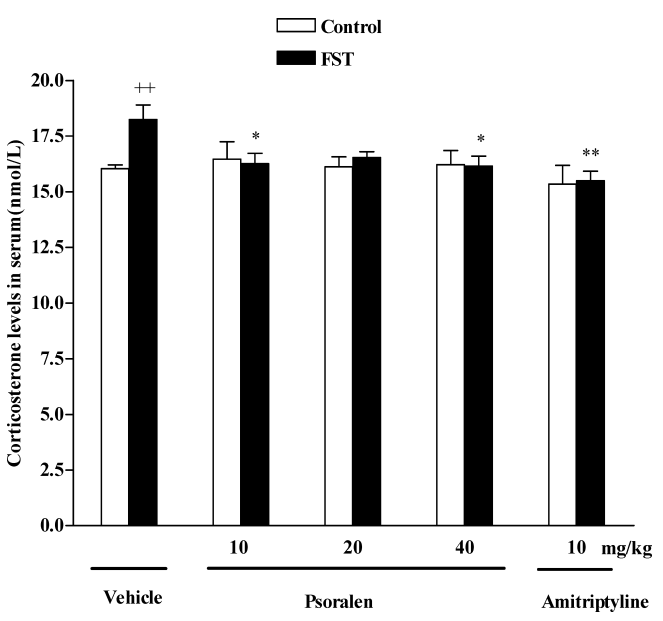

Fig. 5. Effects of Psoralen on Serum Corticosterone Levels in the Mouse FST

Psoralen $(10,20,40 \mathrm{mg} / \mathrm{kg})$, amitriptyline $(10 \mathrm{mg} / \mathrm{kg})$ and water (vehicle) were orally administered for 14 consecutive days, respectively. The data were given as the mean \pm S.E.M. For statistical significance, $* p<0.05$ and $* * p<0.01$ when the drug treated groups were compared with the FST-treated mice (FST vehicle). $++p<0.01$ when the drug treated groups were compared with the non-stressed mice (Control vehicle). The number of animals in each group was 8 .

serum corticosterone levels in the control mice not exposed to FST.

\section{DISCUSSION}

FST is the most widely used model for assessing pharmacological antidepressant activity. In the present study, psoralen decreased immobility and increased swimming in the mouse FST. These behavioral data may confirm previous clinical reports that psoralen had the therapeutic activity in affective disorders. ${ }^{18)}$ On the immobility behavioral measure, psoralen showed no clear dose-response pattern among the treatment times in the mouse FST. Of note, some of depressants failed to consistently reduce immobility time in the FST at pharmacologically relevant doses and times. ${ }^{22,26-29)}$ The positive antidepressant amitriptyline was significant effective after 1-, 3- and 14-d treatment, this result was partly in line with previous studies, indicating that treatment with amitriptyline decreased immobility time in the FST in Naïve Swiss mice. ${ }^{29)}$ However, there was a non-significant trend for an acute treatment of amitriptyline to change immobility time in the FST in Naïve male CF-1 mice. ${ }^{27)}$ These observations indicated that behavioural effects of antidepressant drugs might be influenced by mouse strain, drug administration utilized and drug metabolism in animals. ${ }^{30)}$ On the other hand, FST is described originally by Porsolt et al. and modified by Lucki and co-workers. ${ }^{20-23}$ ) The traditional immobility behaviors may give rise to a false positive effect in the mouse FST. This modified procedure involves more detailed behavioral scoring, which adds evaluation of swimming and climbing to the traditional immobility floating measures. Interestingly, on the swimming behavioral measure, psoralen exhibited an inverted U-shape dose responses after 3, 7, 14-d treatment. The maximal antidepressant action by psoralen was obtained at a dose of $20 \mathrm{mg} / \mathrm{kg}$, and the efficacy by psoralen at $20 \mathrm{mg} / \mathrm{kg}$ was more than that of amitriptyline after 7 , 14-d treatment. Therefore, these data for the first time clearly demonstrated antidepressant-like efficacy for psoralen in the
FST in mice

Furthermore, the scoring behaviors of swimming and climbing give additional information about the mechanism of action that mediates the antidepressant-like effects. ${ }^{22,23}$ ) Swimming is mediated by serotoninergic neurotransmission, while climbing is mediated by norepinephrinergic neurotransmission. ${ }^{22}$ Based on above swimming behavior observation, it is postulated that the antidepressant-like action of psoralen may be mediated by serotoninergic neurotransmission. Interestingly, in the present study, psoralen significantly reversed FST-induced alterations in 5-HT and 5-HIAA levels, as well as 5-HIAA/5-HT ratio in the mouse brain regions. In accordance to the dose responses obtained in the mouse swimming behavior of FST, the effects of 14-d psoralen treatment on 5-HT levels in frontal cortex and hippocampus were clearly inverted U-shaped dose-response relationship, it would appear that psoralen-induced attenuation of swim stress-related decrease in 5-HT levels, at least partly, was indicative of swimming behavioral activity in this experiment. These results noted here were similar to that described in previous studies that examined serotonergic mechanisms of antidepressant drugs in the swimming stressed model of animals. ${ }^{31-33)}$ In addition, MAO activity is associated with the metabolism of monoamine neurotransmitters and has been suggested to be a trait-dependent indicator of vulnerability to psychopathology. ${ }^{34)}$ MAO-A acts preferentially on 5-HT and breaks down 5-HT to 5-HIAA. Our previous studies showed that psoralen possessed in vitro inhibitory actions on MAO-A in rat brain mitochondria ${ }^{16}$ and the total furocoumarins of $P$. corylifolia attenuated stressinduced increases in brain MAO-A activity, ${ }^{7,17)}$ indicating that the decreases observed in brain MAO-A activity could consequently increase brain 5-HT levels after psoralen treatment. These results suggested that psoralen possessed antidepressant-like properties, which were partly mediated by the central serotonergic system.

Evidences from pre-clinical and clinical studies support that there is an impairment of neuroendocrinological function in depression. ${ }^{35)}$ The most frequently occurring neuroendocrinological abnormality in patient with depression is hyperactivity of the HPA axis characterized by hypersecretion of $\mathrm{CRF}^{36)}$ and cortisol. ${ }^{37)}$ The cortisol and corticosterone are two forms of the same agents existing in different species, cortisol in humans and most mammals, corticosterone in mice and rats. Elevated cortisol levels have been the most widely used peripheral marker of stress responses and become a well-established index of the HPA axis activation in psychophysiology research in humans. ${ }^{38,39)}$ It is well known that CRF is a neurotransmitter or neuromodulator in brain and acts within the central nervous system to modulate a number of behavioral, neuroendocrine and autonomic responses to environmental stimulation through its actions on the HPA axis. ${ }^{37)}$ It was reported that the interactions of CRF and serotoninergic systems might be central to the pathophysiology of depression. ${ }^{40)}$ Normalization of these systems is hypothesized to play an important role in mediating the antidepressant activity. ${ }^{41-43)}$ It was found that mice exposed to FST elicited the HPA axis dysfunction, ${ }^{7,44,45)}$ including the elevations of $\mathrm{CRF}^{45-48)}$ and corticosterone in serum. ${ }^{44,49,50)}$ Amitriptyline treatment significantly decreased saliva cortisol concentrations in hypercortisolemically depressed pa- 
tients, ${ }^{51)}$ indicating that reduction of the HPA axis activity in depressed subjects was of primary importance for therapeutic effects. In the present study, administration of psoralen significantly attenuated swim stress-induced increases in serum CRF and corticosterone concentrations, suggesting that psoralen might alter the dysregulated function of the HPA axis induced by FST. Interestingly, the dose-response effect of psoralen on reduction of serum CRF levels was concomitance with that on increase of brain 5-HT contents, as well as on swimming increase, indicating that the serotonergic system and the HPA axis responds with the production of 5-HT and CRF profiles that is characteristic for psoralen applied in the mouse FST. CRF is a neuromodulator in brain and 5-HT transmission is regulated by $\mathrm{CRF}^{47,52)}$ thus biochemical analyses of the related groups of the FST and psoralen suggest that reduction in CRF levels is involved in key biochemical events during psoralen-treated FST mice. Taken together the above studies suggested that psoralen changed immobility and swimming behaviors which might be involved in the normalization of the serotonergic and the HPA axis systems in the mouse FST.

In conclusion, psoralen isolated from the seeds of $P$. corylifolia reduced immobility and increased swimming in the mouse FST. Psoralen treatment attenuated FST-induced alterations in 5-HT and 5-HIAA levels, as well as 5-HIAA/5HT ratio in frontal cortex and hippocampus. Furthermore, psoralen ameliorated FST-induced increases in serum CRF and corticosterone concentrations to normalize the active HPA axis in mice. These results suggested that the antidepressant-like effects of psoralen were mediated by regulating the serotonergic and the HPA axis systems in the mouse FST. This feature of psoralen makes it an attractive candidate for depression treatment. Further investigations to elucidate mechanisms of its actions and to define its clinical efficacy would be highly desirable.

Acknowledgement This work was supported by Hong Kong Jockey Club Charities Trust.

\section{REFERENCES}

1) Chaouloff F., Brain Res. Brain Res. Rev., 18, 1-32 (1993).

2) Firk C., Markus C., Rob R., J. Psychopharmacol., 21, 538-544 (2007).

3) William P., Claudine H., Marc A., Neuropsychobiology, 44, 74-77 (2001).

4) Swiergiel A. H., Leskov I. L., Dunn A. J., Behav. Brain Res., 186, $32-40$ (2008)

5) Grippo A. J., Gerena D., Huang J., Kumar N., Shah M., Ughreja R., Carter C. S., Psychoneuroendocrinology, 32, 966-980 (2007).

6) Jutkiewicz E. M., Wood S. K., Houshyar H., Hsin L. W., Rice K. C., Woods J. H., Psychopharmacology, 180, 215-223 (2005).

7) Chen Y., Kong L. D., Xia X., Kung H. F., Zhang L., J. Ethnopharmacol., 96, 451-459 (2005).

8) Young E. A., Altemus M., Lopez J. F., Kocsis J. H., Schatzberg A. F., DeBattista C., Zubieta J. K., Psychoneuroendocrinology, 29, 1198 1204 (2004).

9) Post A., Ohl F., Almeida O. F., Binder E. B., Rucker M., Welt S., Binder E., Holsboer F., Sillaber I., Psychopharmacology, 180, 150158 (2005)

10) Lowry C. A., J. Neuroendocrinol., 14, 911-923 (2002).

11) Leonard B. E., Eur. Psychiatry, 20, 302-306 (2005).

12) Li S., Wang C., Wang M. W., Murakami Y., Matsumoto K., Pharmacol. Biochem. Behav., 83, 186-193 (2006).

13) Li S., Wang C., Wang M. W., Wei L., Matsumoto K., Tang Y. Y., Life Sci., 80, 1373-1381 (2007).
14) Keeney A., Jessop D. S., Harbuz M. S., Marsden C. A., Hogg S., Blackburn-Munro R. E., J. Neuroendocrinol., 18, 330-338 (2006).

15) Liu Z. L., Zhang X. N., Zhao S. J., Zhou R. X., Di Yi Jun Yi Da Xue Xиe Bao., 25, 751-752 (2005).

16) Kong L. D., Tan R. X., Woo A. Y., Cheng C. H. K., Pharmacol. Toxicol., 88, 75-80 (2001).

17) Chen Y., Wang H. D., Xia X., Kung H. F., Pan Y., Kong L. D., Phytomedicine, 14, 523-529 (2007).

18) Partonen T., Med. Hypotheses., 50, 481-482 (1998)

19) Qiao C. F., Han Q. B., Mo S. F., Song J. Z., Xu L. J., Chen S. L., Yang D. J., Kong L. D., Kung H. F., Xu H. X., Chem. Pharm. Bull., 54, 714-716 (2006).

20) Porsolt R. D., Bertin A., Jalfre M., Archives Internationales de Pharmacodynamie et de Th'erapie, 229, 327-336 (1977).

21) Cryan J. F., Lucki I., J. Pharmacol. Exp. Ther, 295, 1120-1126 (2000).

22) Detke M. J., Rickels M., Lucki I., Psychopharmacology, 121, 66-72 (1995).

23) Lucki I., Behav. Pharmacol., 18, 523-532 (1997).

24) Curzon G., Green A. R., Br. J. Pharmacol., 39, 653-655 (1970).

25) Welch B. L., Welch A. S., Proc. Natl. Acad. Sci. U.S.A., 64, 100-107 (1969).

26) Detke M. J., Johnson J., Lucki I., Exp. Clin. Psychopharmacol., 5, 107-112 (1997)

27) Nielsen D. M., Carey G. J., Gold L. H., Eur. J. Pharmacol., 499, 135 146 (2004).

28) Connor T. J., Kelliher P., Shen Y., Harkin A., Kelly J. P., Leonard B. E. Biochem. Behav., 65, 591-597 (2000).

29) Guo W., Todd K., Bourin M., Hascoet M., Kouadio F., Pharmacol. Biochem. Behav., 54, 725-730 (1996).

30) Benoit P. D., Franck C., Michel B., Petit-Demouliere B, Chenu F., Bowin M., Psychopharmacology (Berl.), 177, 245-255 (2005).

31) Kirby L. G., Lucki I., J. Pharmacol. Exp. Ther., 282, 967-976 (1997).

32) Wang Y. M., Kong L. D., Chen Y. M., Phytother. Res., 19, 526-529 (2005).

33) Veenema A. H., Cremers T. I. F. H., Jongsma M. E., Psychopharmacology, 178, 151-160 (2005).

34) Haier R. J., Buchsbaum M. S., DeMet E., Wu J., Neuropsychobiology, 20, 62-66 (1988)

35) Tichomirowa M. A., Keck M. E., Schneider H. J., Paez-Pereda M., Renner U., Holsboer F., Stalla G. K., J. Endocrinol. Invest., 28, 89-99 (2005).

36) Barden N., J. Psychiatry Neurosci., 29, 185-193 (2004).

37) Holsboer F., Barden N., Endocr. Rev., 17, 187-205 (1996)

38) Kirschbaum C., Hellhammer D. H., Psychoneuroendocrinology, 19 313-333 (1994)

39) van Heeringen K., Audenaert K., de Van W., Verstraete L. A., J. Affect. Disord., 60, 181-189 (2000).

40) De Groote L., Penalva R. G., Flachskamm C., Reul J. M. H. M., Linthorst A. C. E., J. Neurochem., 94, 45-56 (2005).

41) Ayensu W. K., Pucilowski O., Mason G. A., Overstreet D. H., Rezvani A. H., Janowsky D. S., Physiol. Behav., 57, 165-169 (1995).

42) Ducrocq F., Vaiva G., Encephale., 31, 212-226 (2005).

43) Holtzheimer P. E., Nemeroff C. B., NeuroRx., 3, 42-56 (2006).

44) Hall F. S., Sundstrom J. M., Lerner J., Pert A., Pharmacol. Biochem. Behav., 69, 629-634 (2001).

45) Tataroglu O., Aksoy A., Yilmaz A., Canbeyli R., Brain Res., 1001, $118-124$ (2004)

46) Cryan J., Valentino R., Lucki I., Neurosci. Biobehav. Rev., 29, 547569 (2005).

47) Pan Y., Kong L. D., Xia X., Zhang W. Y., Xia Z. H., Jiang F. X., Pharmacol. Biochem. Behav., 82, 686-694 (2005).

48) Slawecki C. J., Thorsell A. K., ElKhoury A., Mathe A. A., Ehlers C. L., Neuropeptides, 39, 369-377 (2005).

49) Racca S., Spaccamiglio A., Esculapio P., Abbadessa G., Cangemi L., DiCarlo F., Portaleone P., Pharmacol. Biochem. Behav., 81, 894-900 (2005).

50) Andrade S., Silveira S. L., Gomez R., Barros H. M. T., Ribeiro M. F. Prog. Neuropsychopharmacol. Biol. Psychiatry, 31, 613-621 (2007).

51) Heuser I. J., Schweiger U., Gotthardt U., Schmider J., Lammers C. H., Dettling M., Yassouridis A., Holsboer F., Am. J. Psych., 153, 93-99 (1996).

52) Price M. L., Kirby L. G., Valentino R. J., Lucki I., Psychopharmacology, 162, 406-414 (2002). 